\title{
TRANSIENT RESPONSE OF LAMINATED COMPOSITE SPHERICAL SHELL CAP
}

\author{
K.S.Sai Ram ${ }^{1}$, T.A.V.Vijaya Jyothi ${ }^{2}$ \\ ${ }^{1}$ Professor, Department of Civil Engineering, RVR \& JC College of Engineering, Chowdavaram, Guntur - 522 019, India \\ ${ }^{2}$ Post-graduate Student, Department of Civil Engineering, RVR \& JC College of Engineering, Chowdavaram, Guntur- \\ 522019, India
}

\begin{abstract}
The transient behaviour of laminated composite spherical shell cap is investigated using the finite element method. An eight node degenerated isoparametric shell element is considered with five degrees of freedom at each node. The governing equations of forced vibration are solved using the Newmark's direct integration method. Results are presented for dynamic response of deflection and stresses of orthotropic and laminated spherical shell caps subjected to suddenly applied uniform normal pressure.
\end{abstract}

Keywords: Transient response, Spherical shell cap, Forced vibration, Composite shell, Finite element method

\section{INTRODUCTION}

Fibre reinforced plastic laminated composite materials are being increasingly used in aerospace and other applications due to their superior properties such as high specific strength, high specific stiffness and low specific density. They, in the form of shells, find application in aerospace and other industries. Spherical shells are used for many applications such as aerospace vehicles, roof domes, pressure vessels and submarines. The study of forced vibration of composite spherical shell cap is an important engineering problem.

The forced vibration of laminated composite spherical shell cap has been considered by few researchers. Sun and Sun [1] investigated the dynamic response of laminated composite shells subjected to axially symmetric dynamic loadings using the classical method of separation of variables. A specific example of simply supported laminated shell subjected to suddenly applied dynamic pressure is solved. Sheinman and Greif [2] considered the free and forced vibration of thin walled shells of revolution using Hamilton's variational principle. The equations do not include the effect of transverse shear deformation and rotary inertia. Results are presented mostly for cylindrical shells. A result showing the dependence of fundamental frequency on fiber orientation is given for simply supported spherical dome. Wu et. al. [3] investigated the natural frequencies and the dynamic response of thin laminated composite shells of general form using a high-order curved shell finite element. Numerical results are presented for cylindrical shells, shells of positive and negative Gauss curvature and shells of translation. An example for transient response of spherical shell panel is given. Chao and Tung [4] studied the dynamic response of orthotropic hemispherical shells subjected to idealized step pressure, rectangular pressure pulse and realistic blast loading. $\mathrm{Xu}$ and Chia [5] investigated nonlinear vibration of thin laminated spherical caps with flexible supports using a Fouier-Bessel series solution . Numerical results for non-linear free vibration of laminated spherical caps are presented for various values of cap rise , number of layers, material properties and in-plane edge / rotational stiffnesses. Cheung and $\mathrm{Fu}[6]$ derived the non-linear axisymmetric dynamic governing equations for symmetric cross-ply shallow spherical caps. Numerical results for dynamic response and dynamic buckling of spherical caps with circular holes are presented. Sai Ram and Sreedhar Babu [7] investigated the free vibration of composite spherical shell cap with and without a cutout using finite element method based on higher-order shear deformation theory.

In this paper, the transient behaviour of laminated composite spherical shell cap is investigated using the finite element method based on first-order shear deformation theory. An eight node degenerated isoparametric shell element is considered with five degrees of freedom at each node. The governing equations of forced vibration are solved using the Newmark's direct integration method. Dynamic response of deflection and stresses are studied for orthotropic and symmetrically and anti-symmetrically laminated cross-ply spherical shell caps, with simply supported and clamped boundary conditions, subjected to suddenly applied uniform normal pressure. Dynamic load factors for deflection and stresses are presented.

\section{ANALYSIS}

Consider a laminated composite shell (Fig.1) of uniform thickness, consisting of a number of thin laminae, each of which may be arbitrarily oriented at an angle ' $\theta$ ' with 
reference to the $\mathrm{x}$-axis of the local co-ordinate system . The displacements along the local coordinate axes $\mathrm{x}, \mathrm{y}$ and $\mathrm{z}$ at any point in the shell are assumed as

$$
\mathrm{u}=\mathrm{u}_{0}+\mathrm{z} \theta_{\mathrm{y}} ; \mathrm{v}=\mathrm{v}_{0}-\mathrm{z} \theta_{\mathrm{x}} ; \mathrm{w}=\mathrm{w}_{0}
$$

The complete governing equations of the laminated composite are given in ref [ 7].

An eight noded degenerated isoparametric shell element $[9,10]$ is considered in the present analysis. Five degrees of freedom are considered at each node. The stiffness matrix and nodal load vector of the element are derived using the principle of minimum potential energy. The geometry of the element is defined by the global coordinates $\mathrm{X}, \mathrm{Y}$ and $\mathrm{Z}$. The complete finite element formulation to obtain stiffness matrix [Ke], mass matrix $[\mathrm{Me}]$ and load vector $\{\mathrm{Fe}(\mathrm{t})\}$ of the element are given in ref [ 7].

Stiffness matrix $[\mathrm{Ke}]$, mass matrix $[\mathrm{Me}]$ and load vector $\{\mathrm{Fe}(\mathrm{t})\}$ of individual elements are assembled to obtain Global stiffness matrix $[\mathrm{K}]$, and Global mass matrix $[\mathrm{M}]$ and Global load vector $\{\mathrm{F}(\mathrm{t})\}$. The governing equation of motion for forced vibration is given by

$$
[K]\{U\}+[M]\{\ddot{U}\}=\{F(t)\}
$$

where

$\{\mathrm{U}\}=$ Global displacement vector

$\{\ddot{U}\}=$ Global acceleration vector

The above governing equation is solved using Newmark's direct integration method [11].

\section{RESULTS AND DISCUSSION}

The analysis described in the previous sections is applicable to the forced vibration of various types of laminated composite shells . In the present investigation, the transient behaviour of laminated composite spherical shell cap (Fig.2) is investigated. The local coordinate axes $\mathrm{x}$ and $\mathrm{y}$ are oriented along circumferential and meridional directions, respectively. Fibre orientation $\square$ is measured with reference to circumferential direction, i.e. $x$-axis. Hence, fibre orientation $0^{0}$ means that the fibres are along the circumferential direction, whereas fibre orientation $90^{\circ}$ means that the fibres are along the meridional direction. It is assumed that fibre volume in a lamina is constant along the meridian. Results are presented for orthotropic and cross-ply laminated composite spherical shell cap with simply supported and clamped boundary conditions. UOi and VOi are restrained along the supported edge. The following lamina material properties are used throughout the investigation. $\mathrm{E} 1=172369 \mathrm{MPa}, \mathrm{E} 2=6895 \mathrm{MPa}, \mathrm{G} 12=\mathrm{G} 13=$ $3448 \mathrm{MPa}, \mathrm{G} 23=1379 \mathrm{MPa}, \nu 12=0.25$ and $\mathrm{\rho k}=16 \times 10$
${ }^{10} \mathrm{~N} . \mathrm{s}^{2} / \mathrm{mm}^{4}$. For finite element analysis, the spherical shell cap is considered to have a circular cutout at the crown (Fig.2a) with $\square 0=0.001 \square 1$ and the value of $\square \square \square$ is considered as 10 The radius of curvature and the thickness of the spherical shell cap considered are $1000 \mathrm{~mm}$ and $5 \mathrm{~mm}$ respectively. The intensity of suddenly applied uniform normal pressure $(\mathrm{p} 0)$ is $0.1 \mathrm{~N} / \mathrm{mm}^{2}$. Convergence studies were carried out in ref. [8] and the entire spherical shell cap is modeled with 112 elements, a quarter of which is shown in Fig.2b. The validity of the present finite element analysis is verified by means of the following problems.

An isotropic simply supported square plate of size $25 \mathrm{~cm} \mathrm{x}$ $25 \mathrm{~cm}$, thickness $={ }^{5 \mathrm{~cm}}, v_{12}=0.25, \mathrm{E}=2.1 \times 10^{6} \mathrm{~N} / \mathrm{cm}^{2}$ and $\square \square$ $=8 \times 10^{-6} \mathrm{~N} \mathrm{sec} / \mathrm{cm}^{4}$ is analysed subjected to a uniformly distributed pulse load. A quarter of the plate is discretised with 64 elements. The results obtained are compared with those in [12] and are shown in Table 1. Next, a simply supported $\left[0^{0} / 90^{0}\right]$ spherical shell panel subjected suddenly applied uniform normal pressure is considered. A quarter of the panel is analysed with 4 elements. The central deflection is plotted with time (Fig.3) and is compared with that available in reference [13]. $\mathrm{R}=100 \mathrm{~cm}, \mathrm{a}=\mathrm{b}=50 \mathrm{~cm}, \mathrm{~h}=1 \mathrm{~cm}, \mathrm{E} 1=25 \times 10^{6}$ $\mathrm{N} / \mathrm{cm}^{2}, \mathrm{E} 2=10^{6} \mathrm{~N} / \mathrm{cm}^{2}, \mathrm{G} 12=\mathrm{G} 13=0.5 \times 10^{6} \mathrm{~N} / \mathrm{cm}^{2}, \mathrm{G} 23=$ $0.2 \times 10^{6} \mathrm{~N} / \mathrm{cm}^{2}, v 12=0.25$ and $\rho=1 \mathrm{~N} . \mathrm{s}^{2} / \mathrm{cm}^{4}$. From results presented in Table 1 and Fig.3, it is evident that the present finite element analysis is accurate and reliable.

The response of deflection of the crown and the stress $\square \mathrm{x}$ at the top of the crown of simply supported and clamped orthotropic and laminated spherical shell caps are 6 shown in Figs. 4-8. The dynamic load factors for deflection and stresses are shown in Table 2. From the results presented, the following observations may be made.

In the case of $\left[0^{0}\right]$ spherical shell cap (Fig.4), the shell cap deflects more downwards than upward during vibration. The normal stress at the top of the crown is predominantly compressive in nature. The responses are similar for simply supported and clamped boundary conditions. The variations of deflection and normal stress at top of the crown with time are almost repeating without appreciable change. The dynamic load factors for normal stress at the top are very high ,viz., 47.49 and 41.03 for simply supported and clamped boundary conditions, respectively.

In the case of $\left[90^{0}\right]$ spherical shell cap (Fig.5), the shell cap deflects more downwards than upward during vibration. The normal stress at the top of the crown is predominantly compressive in nature. The responses are dissimilar for simply supported and clamped boundary conditions. The variations of deflection and normal stress at the top of the crown are repeating with the time with appreciable change.

In the case of $\left[0^{\circ} / 90^{\circ}\right]$ spherical shell cap (Fig.6), the shell cap deflects more downwards than upward during vibration. The 
normal stress at top of the crown is predominantly tensile in nature. The responses are quite different for simply supported and clamped boundary conditions. The variations of deflection and normal stress at the top of the crown are not repeating with time and not even one cycle of vibration is completed in 25 seconds.

In the case of $\left[90^{\circ} / 0^{0}\right]$ spherical shell cap (Fig.7), the shell cap deflects only downwards during vibration. The normal stress at the top of the crown is predominantly compressive in nature. The responses are similar for simply supported and clamped boundary conditions. The variations of deflection and normal stress at the top of the crown with time are almost repeating without appreciable change.

In the case of $\left[0^{0} / 90^{\circ} / 0^{0}\right]$ spherical shell cap (Fig.8), the shell cap deflects more downwards than upward during vibration. The normal stress at the top at the crown is predominantly compressive in nature. The responses are similar for simply supported and clamped boundary conditions. The variations of deflection and normal stress at the top of the crown with time are almost repeating without appreciable change.

\section{CONCLUSION}

The transient behavior of laminated composite spherical shell cap is analysed using the finite element method based on firstorder shear deformation theory. An eight-node degenerated isoparametric shell element is considered with five degrees of freedom at each node. The governing equation of forced vibration is solved using by direct integration using Newmark's numerical integration method. Responses of deflection and stresses are presented for orthotropic and laminated symmetric/ anti-symmetric spherical shell caps with simply supported and clamped boundary conditions subjected to transient uniform normal pressure. From the results presented, the following conclusions may be made.

1. During vibration, the spherical shell caps considered deflected downward more than upwards.

2. Higher amplitude of vibration is observed in the case of orthotropic spherical shell caps with fibres along circumferential direction $\left(0^{0}\right)$. The stresses developed in these shell caps are less. This is due to little stiffness in the meridonial direction.

3. The time taken to complete one cycle of vibration is only a fraction of a second for $\left[0^{0}\right]$ and $\left[90^{\circ}\right]$ spherical shell caps whereas it is about 28 seconds in the case of $\left[0^{0} / 90^{0} / 0^{0}\right]$ spherical shell cap and it is still higher for $\left[0^{0} / 90^{\circ}\right]$ and $\left[90^{\circ} / 0^{0}\right]$ spherical shell caps.

\section{NOTATION}

$\mathrm{E} 1, \mathrm{E} 2$

Young's moduli along 1 and 2 axes of a

lamina

FEM

Finite element method

G12, G13, G23 Shear moduli in 1-2, 1-3 and 2-3 planes of a lamina, respectively

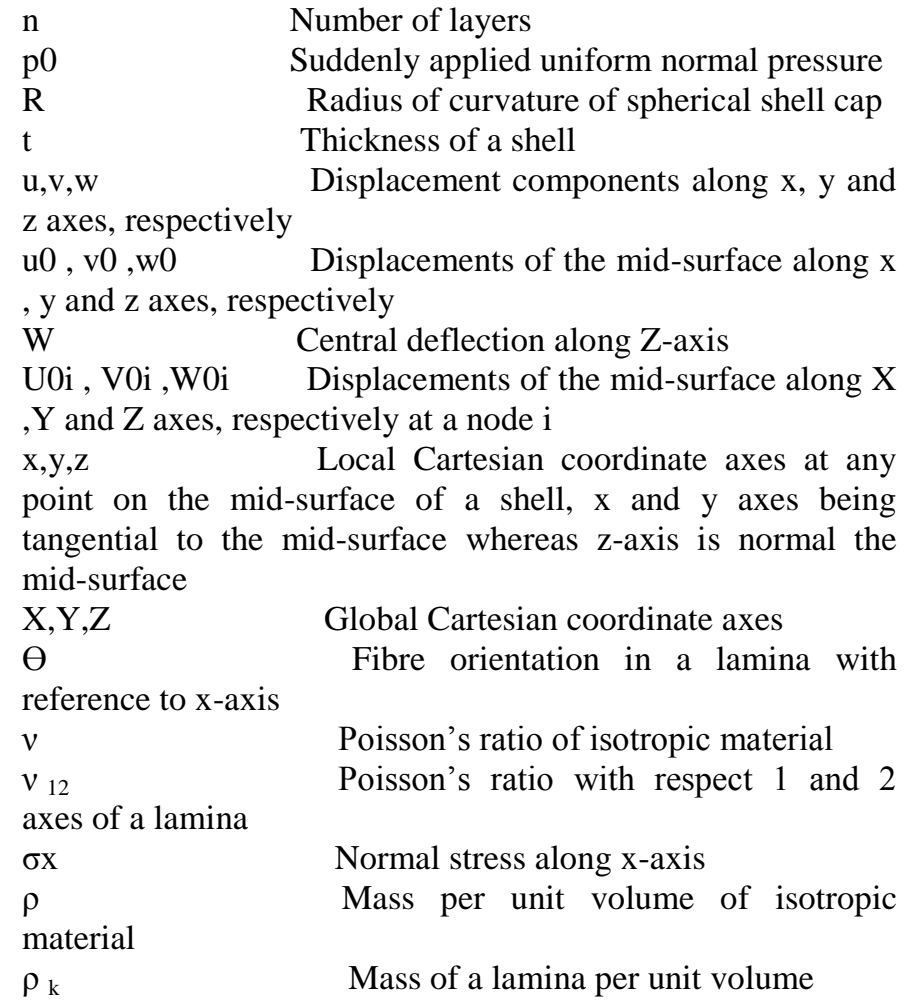

\section{REFERENCES}

[1] Sun, C.T. and Sun, P.W., "Laminated Composite Shells Under Axially Symmetric Dynamic Loadings", Journal of Sound and Vibration,Vol.35,1974, pp.395-415.

[2] Sheinman,I.and Greif, S.,"Dynamic analysis of laminated shells of revolution", Journal of Composite Materials, Vol.18,1984,pp.200-215.

[3] Wu, Y.C. ,Yang, T.Y. and Saigal,S., "Free and forced vibrations of non-linear dynamics of composite shell structures", Journal of Composite Materials, Vol.21,1987,pp.898-909.

[4] Chao,C.C. and Tung, T.P.,"Step pressure and blast responses of clamped orthotropic hemispherical shells", Int. J. Impact Engng,Vol.8,1989,pp. 191-207.

[5] Xu,C.S. and Chia, C.Y. , "Non-linear vibration of symmetrically laminated spherical caps with flexible supports", Acta Mechanica,Vol.94,1992,pp.59-72.

[6] Cheung, Y.K. and Fu,Y.M.," Non-linear static and dynamic analysis for laminated annular spherical caps of moderate thickness", Non-linear Dynamics, Vol.8,1995, pp.251-268.

[7] Sai Ram, K.S. and Sreedhar Babu,T.," Free vibration of composite spherical shell cap with and without a cutout", Computers and Structures, Vol.80,2002,pp.1749-1756.

[8] Sai Ram, K.S. and , Sreedhar Babu, T., "Study of bending of laminated composite shells. Part II : Shells with a cutout", Composite Structures, Vol.51,2001, pp.117-126. 
[9] Cook, R.D., Malkus,D.S. and Plesha, M.E.," Shells, Concepts and applications of Finite Element Analysis", John Wiley, 1989.

[10] Zienkiewicz, O.C.and Taylor, R.L.," Shells as a special case of three-dimensional analysis, The Finite element method", Vol.2, McGraw- Hill, 1991.

[11] Bathe, K.J.," Finite element procedures in engineering analysis", Prentice-Hall,1982.
[12] Reddy, J.N. ," Dynamic (Transient) analysis of layered anisotropic composite material plates", Int.J.Num.Meth.Engng., Vol.19,1983,pp. 237-255.

[13] Reddy, J.N. and Chandrasekhara, K. ," Geometrically non-linear transient analysis of laminated doubly curved shells", Int.J.Non-linear Mechanics,Vol.20,1985,pp.79-90.

Table 1 Comparison of results of a simply supported isotropic square plate subjected to uniformly distributed pulse load of intensity $10 \mathrm{~N} / \mathrm{cm}^{2}$

\begin{tabular}{|c|c|c|}
\hline Time $(\mu \mathrm{s})$ & $\begin{array}{c}\text { Central deflection } \\
\mathrm{cm}\left(* 10^{3}\right)\end{array}$ & $\begin{array}{l}\text { Normal stress at } \\
\text { centre } \mathrm{N} / \mathrm{cm}^{2}\end{array}$ \\
\hline 40 & $0.1372(0.1375)$ & $5.630(5.799)$ \\
\hline 80 & $0.7372(0.7388)$ & $60.87(61.49)$ \\
\hline 120 & $1.3804(1.3844)$ & $120.19(120.2)$ \\
\hline 160 & $1.6207(1.6232)$ & $137.01(137.8)$ \\
\hline 200 & $1.3626(1.3671)$ & $120.24(120.6)$ \\
\hline
\end{tabular}

Values in ( ) are from ref. [12]

Table 2 Dynamic load factors of deflection and stress

\begin{tabular}{|c|c|c|c|c|}
\hline \multirow{2}{*}{$\begin{array}{l}\text { Laminate } \\
\text { configuration }\end{array}$} & \multicolumn{2}{|c|}{ Simply supported } & \multicolumn{2}{c|}{ Clamped } \\
\cline { 2 - 5 } & $\begin{array}{l}\text { Deflection at } \\
\text { the crown }\end{array}$ & $\begin{array}{l}\sigma_{\mathrm{x}} \text { at the top of } \\
\text { the crown }\end{array}$ & $\begin{array}{l}\text { Deflection at } \\
\text { the crown }\end{array}$ & $\begin{array}{l}\sigma_{\mathrm{x}} \text { at the top of } \\
\text { the crown }\end{array}$ \\
\hline$\left[0^{\circ}\right]$ & 2.23 & 47.50 & 2.19 & 41.50 \\
\hline$\left[90^{\circ}\right]$ & 2.75 & 2.35 & 2.73 & 2.46 \\
\hline$\left[0^{\circ} / 90^{\circ}\right]$ & 1.54 & 2.16 & 2.85 & 2.27 \\
\hline$\left[90^{\circ} / 0^{\circ}\right]$ & 2.39 & 2.37 & 2.41 & 2.42 \\
\hline$\left[0^{\circ} / 90^{\circ} / 0^{\circ}\right]$ & 2.57 & 1.53 & 2.63 & 1.67 \\
\hline
\end{tabular}




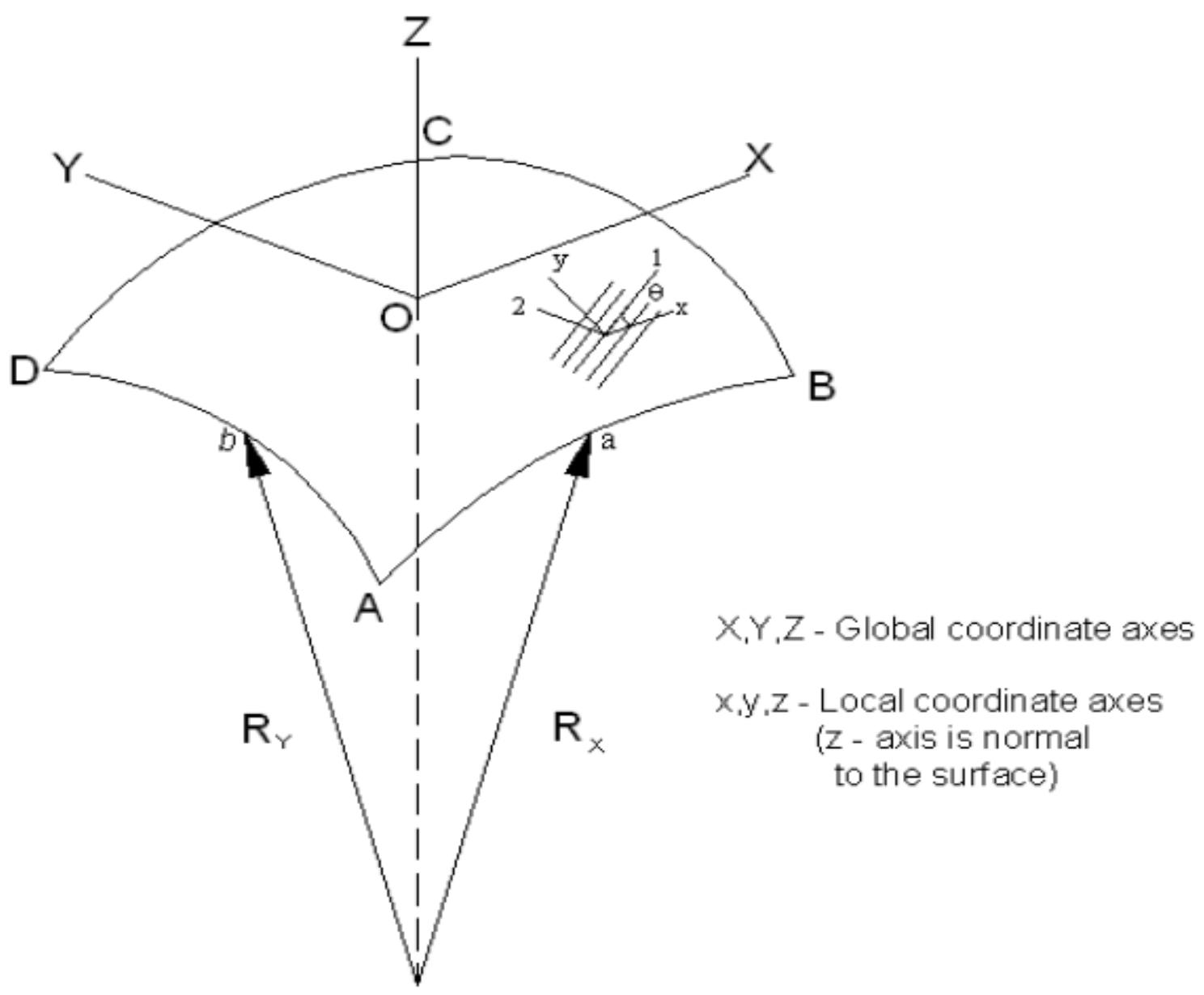

(a) Shell geometry

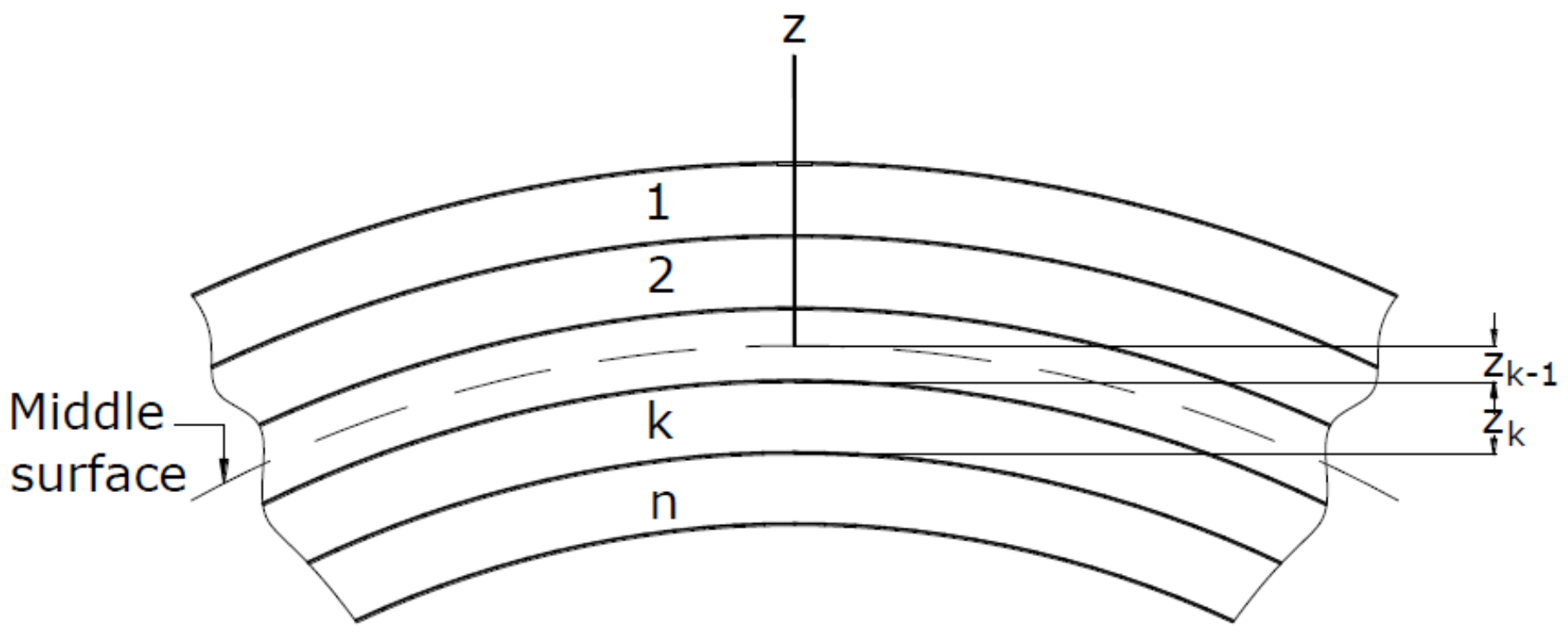

(b) Layer details

Fig.1 Laminated composite shell 


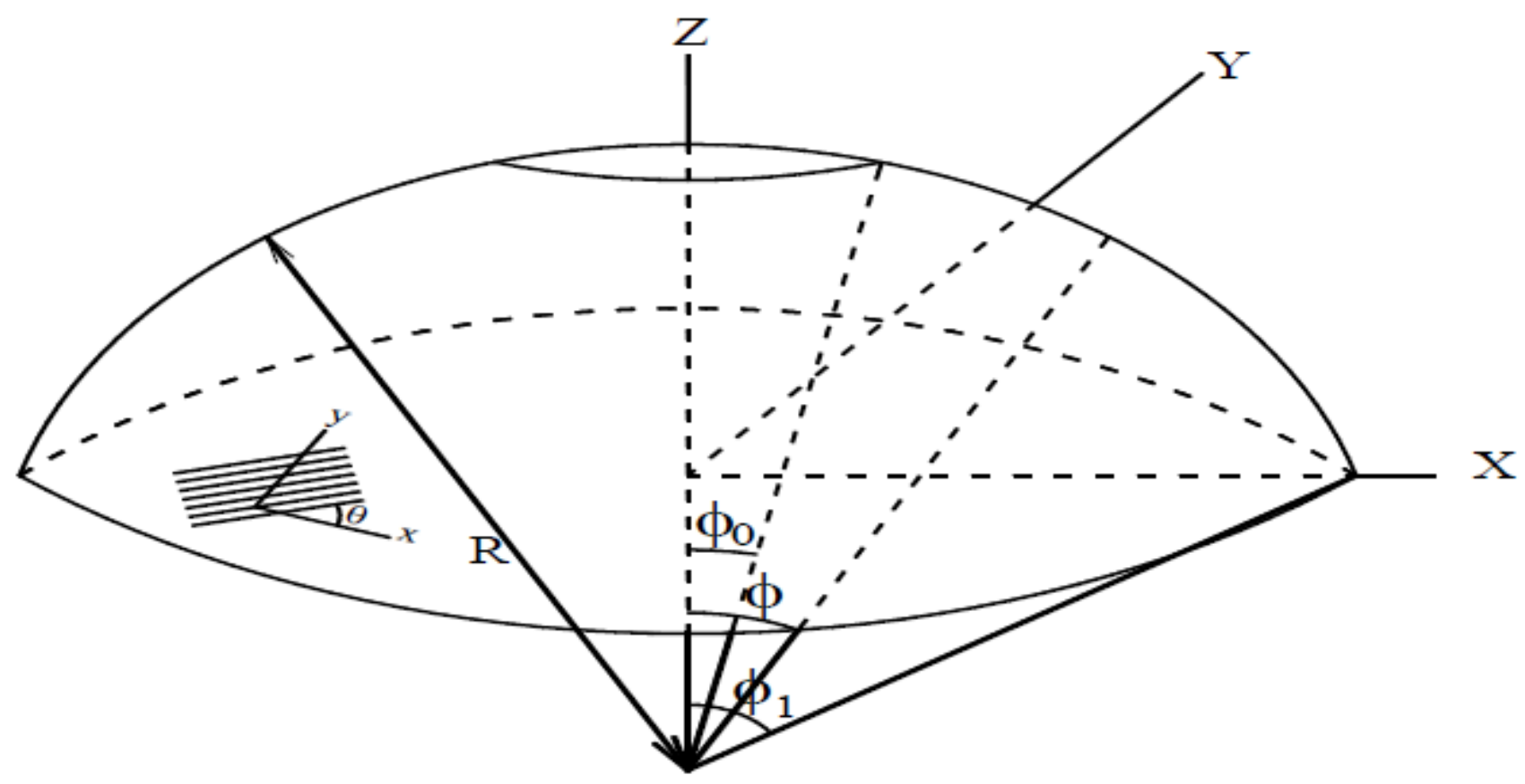

(a) Geometry

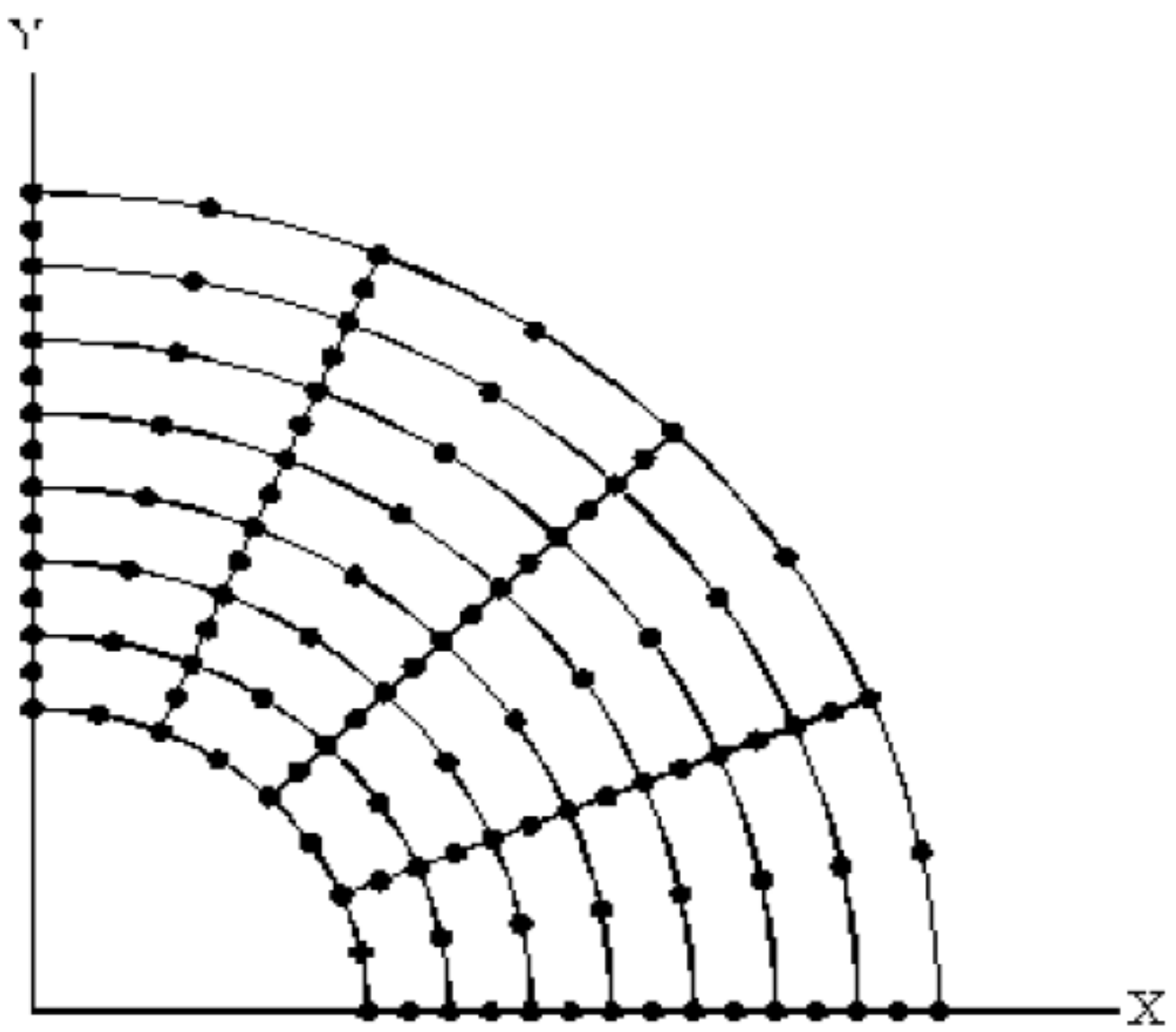

(b) Discretisational details for a quarter

Fig.2 Laminated composite spherical shell cap 


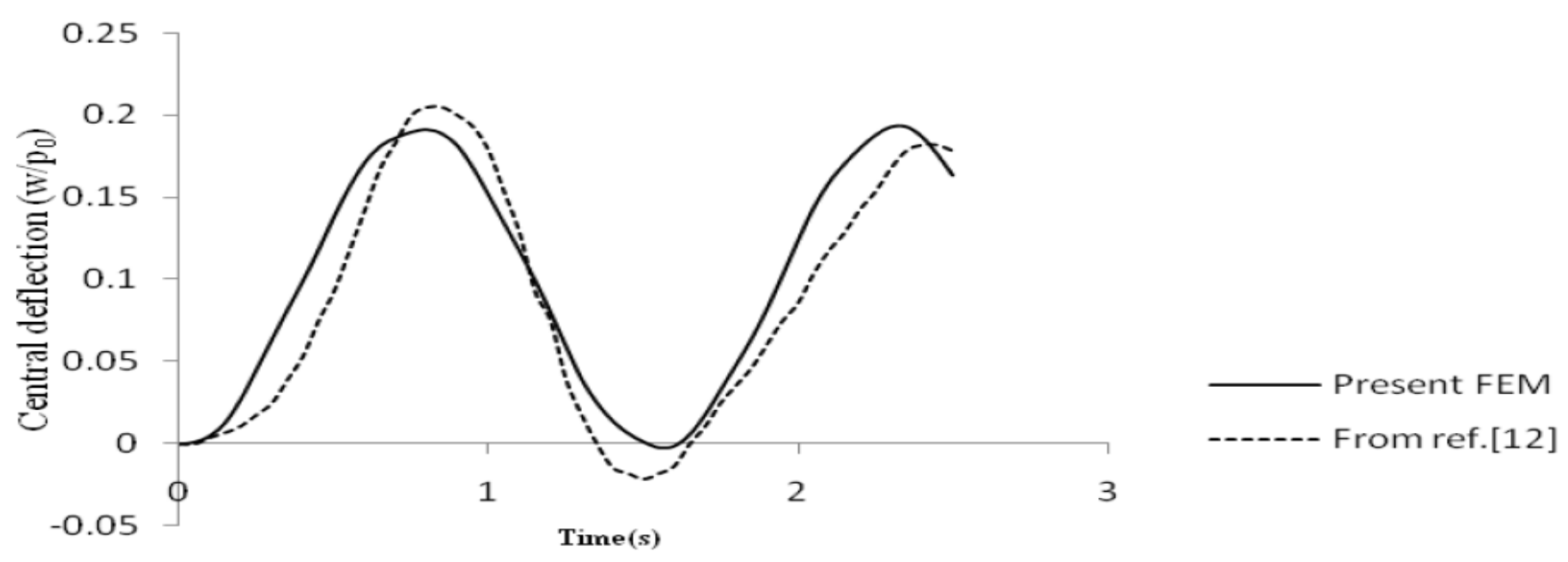

Fig.3 Central deflection verses time for $\left[0^{\circ} / 90^{\circ}\right]$ spherical shell panel

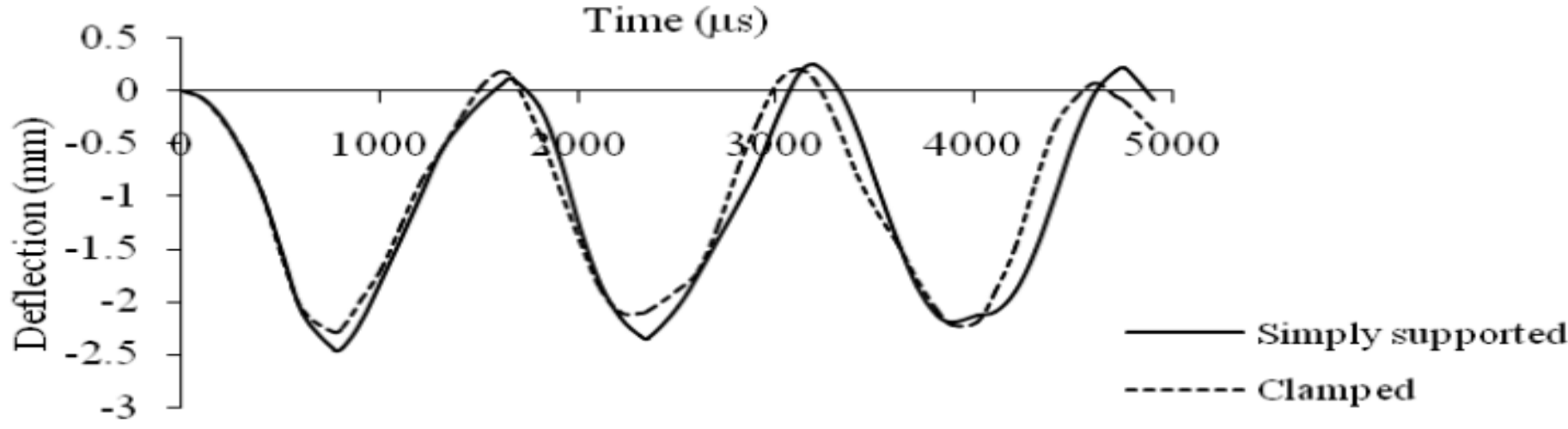

(a) Deflection at the crown

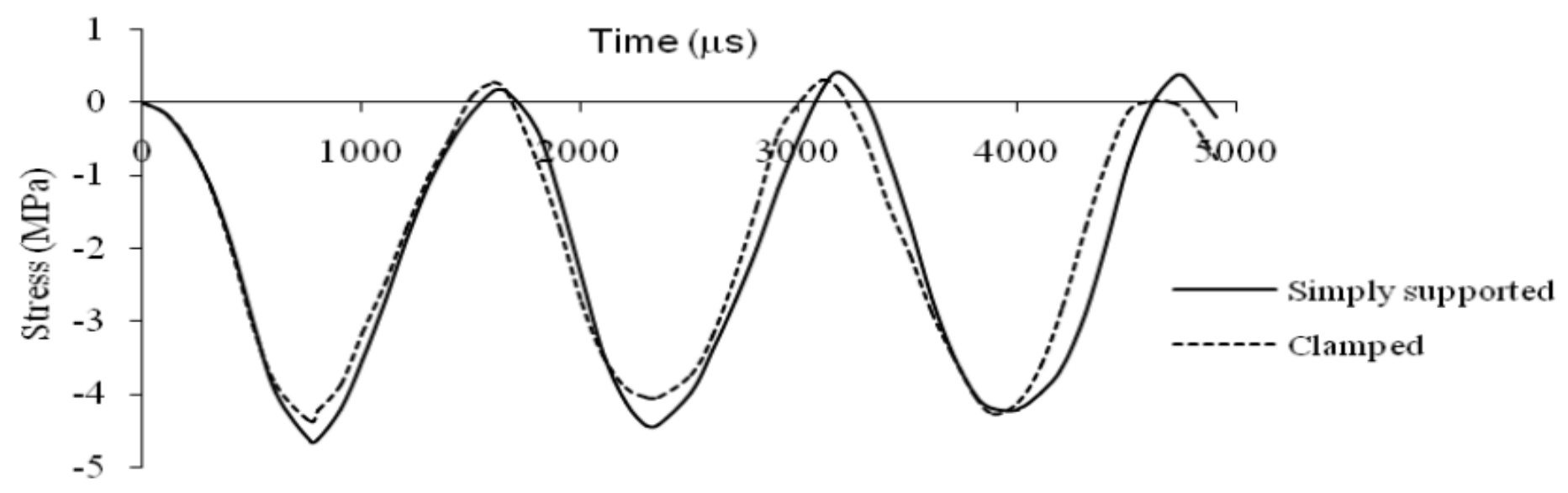

(b) Stress $\sigma_{\mathrm{x}}$ at the top of the crown

Fig. 4 Dynamic response of $\left[0^{0}\right]$ spherical shell cap 


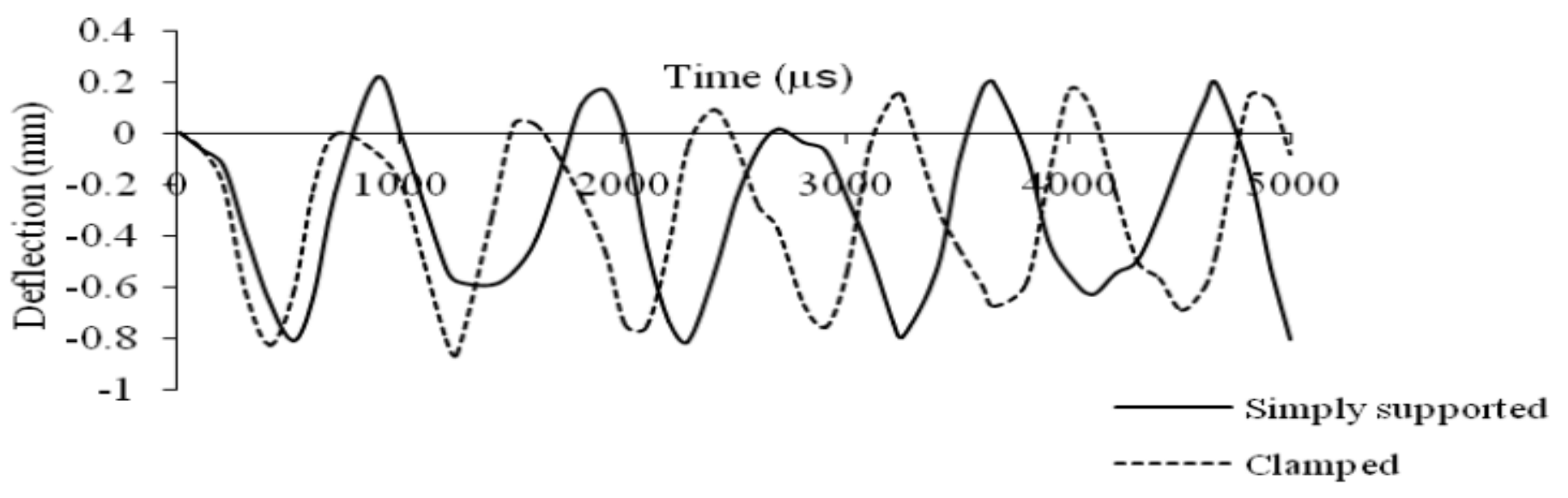

(a) Deflection at the crown

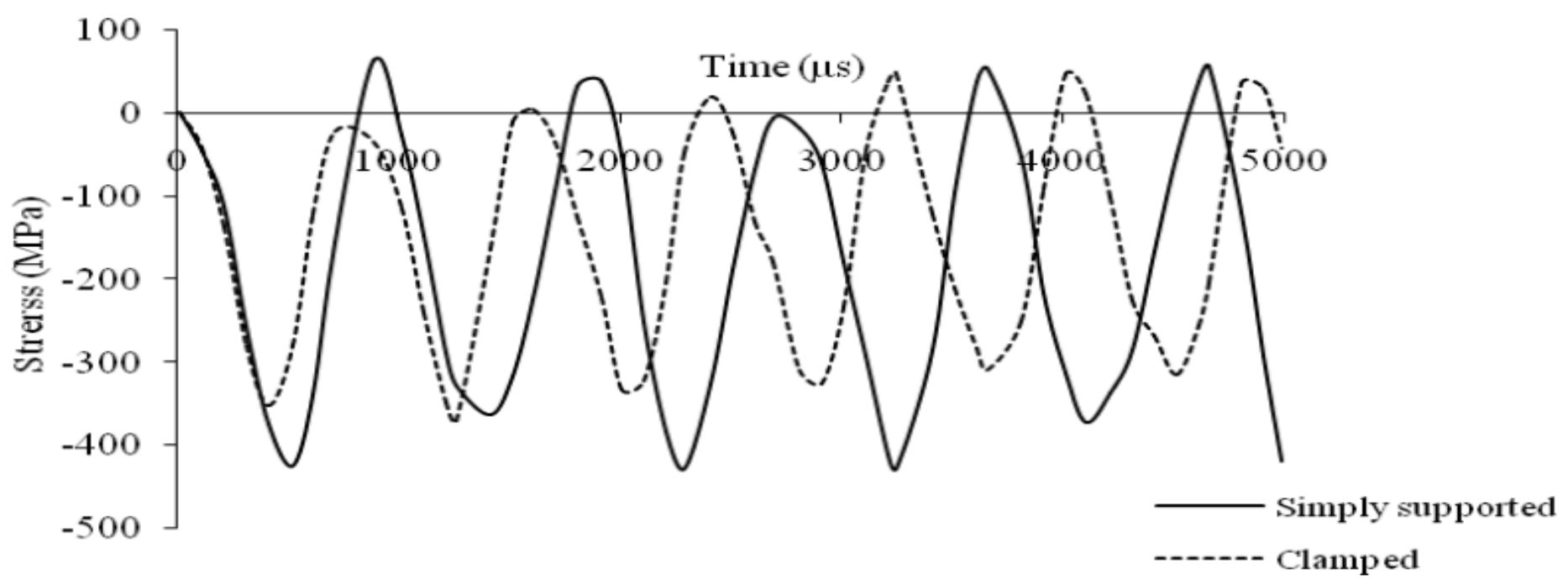

(b) Stress $\sigma_{\mathrm{x}}$ at the top of the crown crown

Fig. 5 Dynamic response of $\left[90^{0}\right]$ spherical shell cap

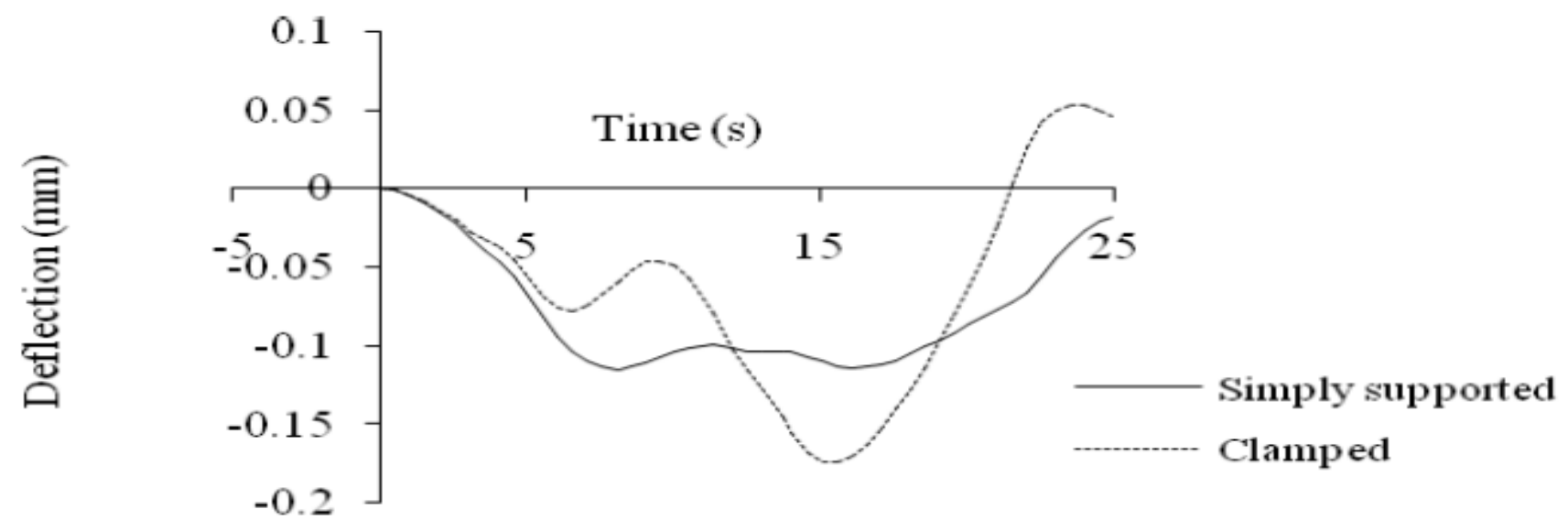

(a) Deflection at the crown 


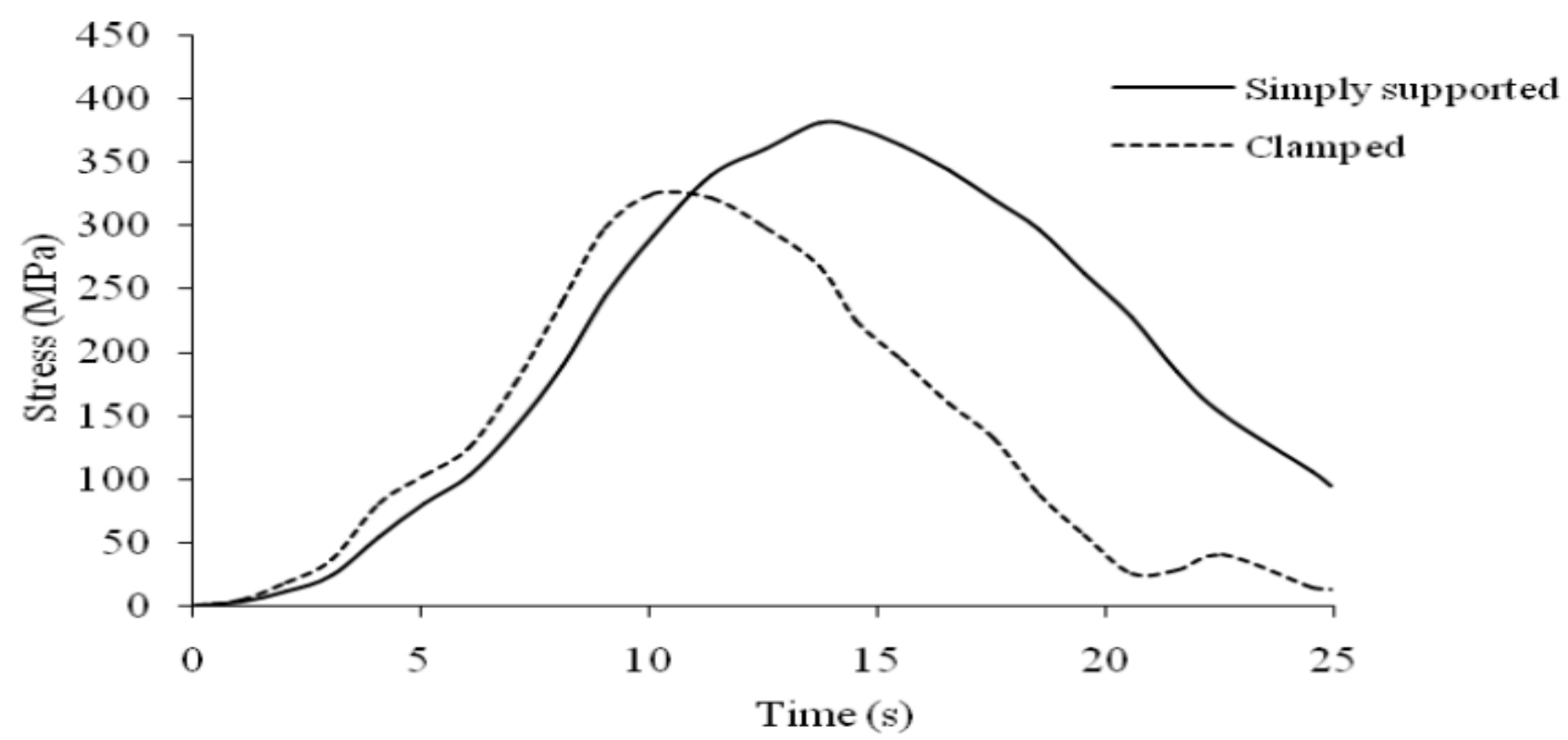

(b) Stress $\sigma_{\mathrm{x}}$ at the top of the crown

Fig.6 Dynamic response of $\left[0^{\circ} / 90^{\circ}\right]$ spherical shell cap

Time $(s)$

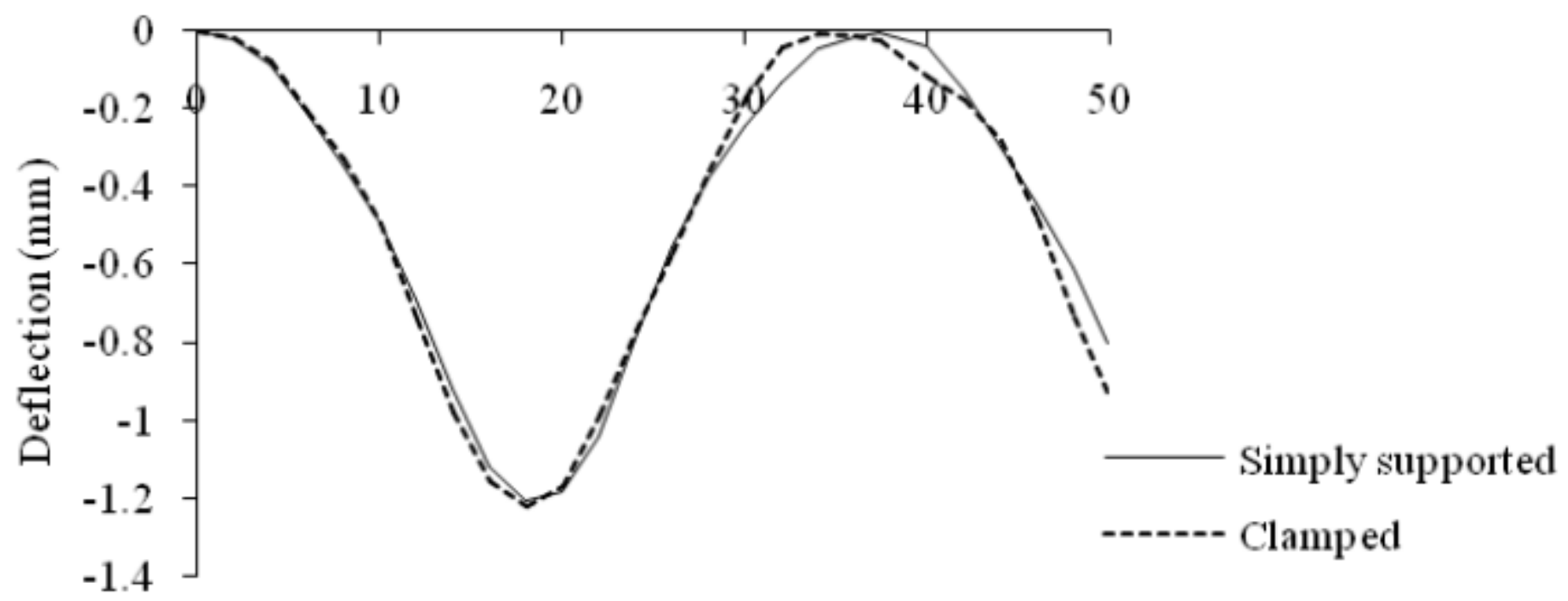

(a) Deflection at the crown 


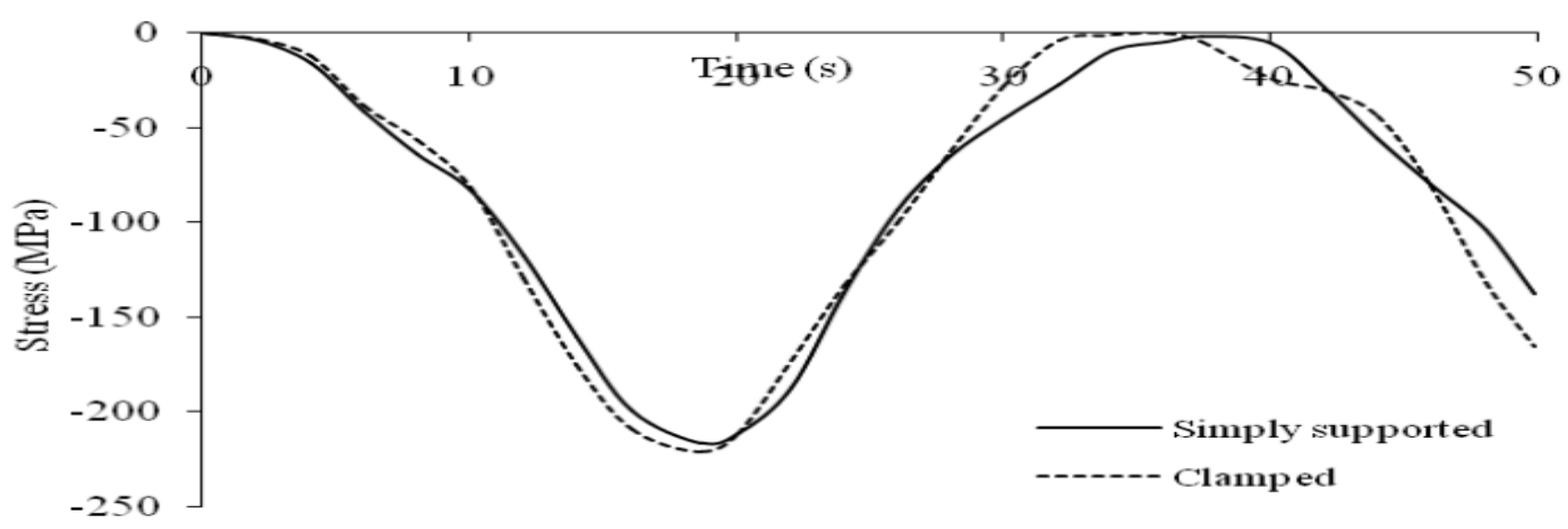

(b) Stress $\sigma_{x}$ at the top of the crown

Fig.7 Dynamic response of $\left[90^{0} / 0^{0}\right]$ spherical shell cap

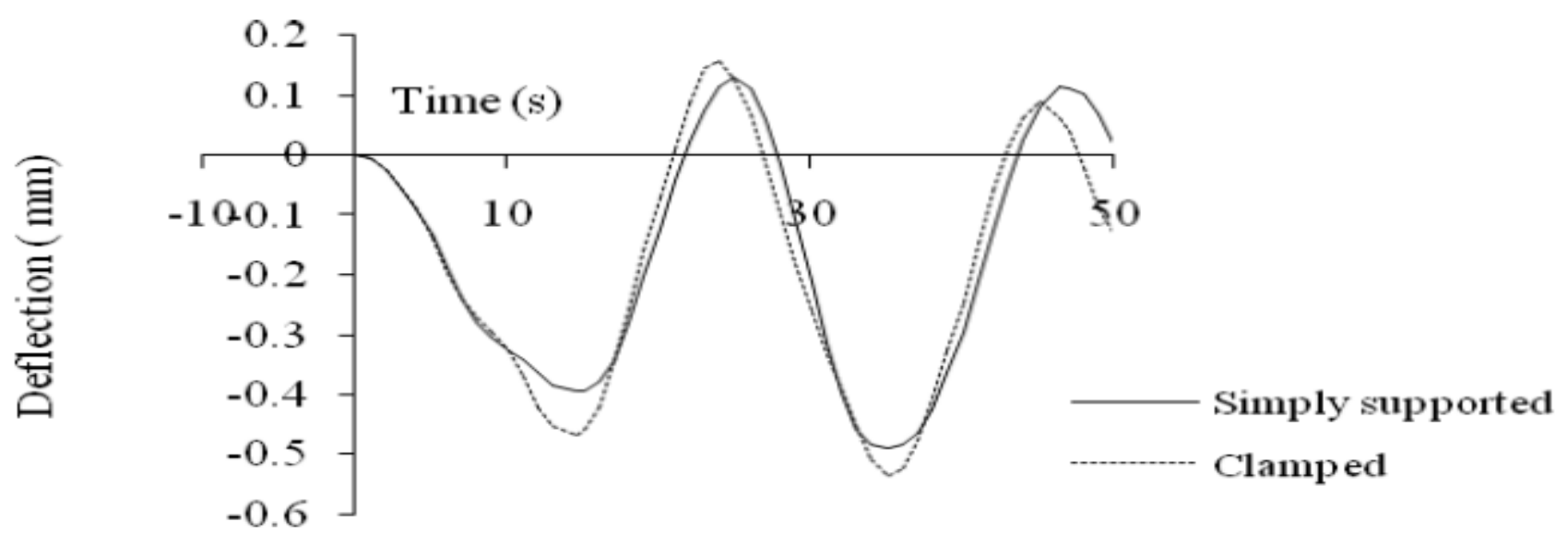

(a) Deflection at the crown

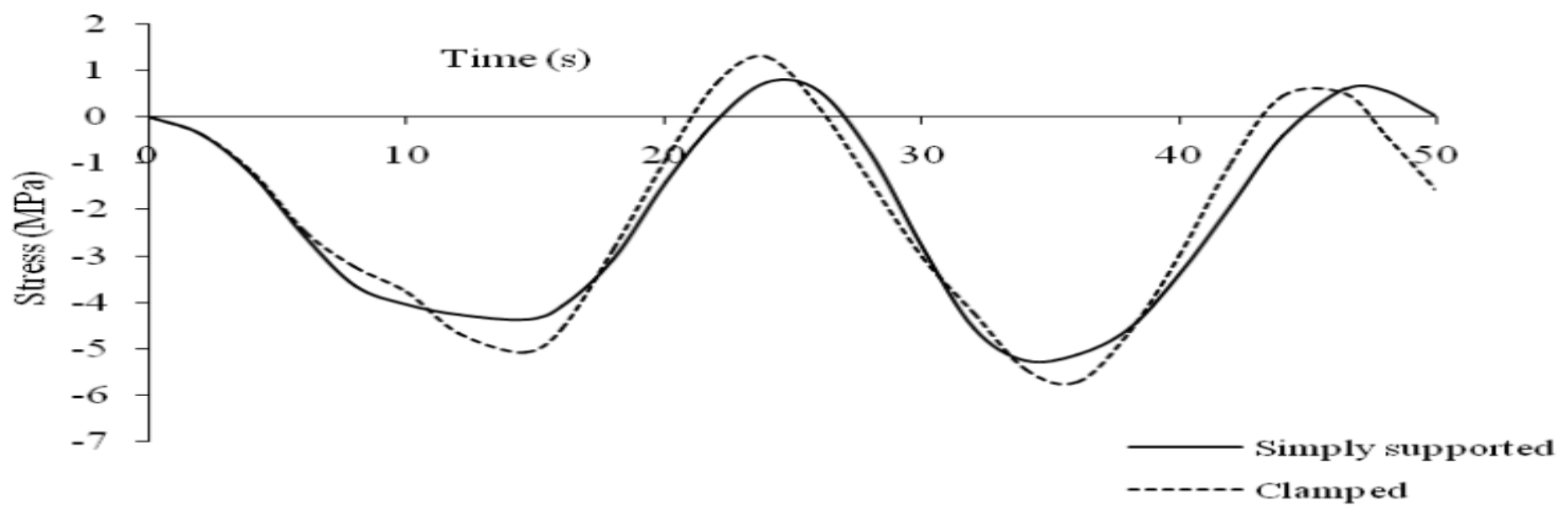

(b) Stress $\sigma_{x}$ at the top of the crown

Fig.8 Dynamic response of $\left[0^{0} / 90^{0} / 0^{0}\right]$ spherical shell cap 